\title{
Carcinoma de células claras renales metastásico a mama
}

\author{
Clear cell renal carcinoma metastatic to the breast
}

\author{
Gustavo Matute ${ }^{1}$, Oscar Raigoza², Daniela Bertel ${ }^{3}$ \\ Médico, especialista en Patología, profesor titular Facultad de Medicina. Universidad Pontificia Bolivariana. Medellín, Colombia \\ 2 Médico, especialista en Radiología. Dinámica IPS. Medellín, Colombia \\ 3 Médica, residente de Patología. Grupo de Investigación en Histopatología; Facultad de Medicina, Universidad de Cartagena, \\ Cartagena, Colombia.
}

\begin{abstract}
Resumen
Introducción. La metástasis a mama de una neoplasia de origen extramamario, es una entidad infrecuente, que representael 0,2 al I,3\% de los tumores malignos no hematológicos en mama reportado en series de casos. En el $88,2 \%$ de los casos se trata de pacientes con historia de un tumor primario previamente tratado y un II,8\% a tumor primario oculto. Los principales orígenes primarios de estas metástasis son el melanoma cutáneo y los carcinomas de origen pulmonar y ginecológico.

Caso clínico. Se expone el caso de una mujer de 59 años de edad, con antecedente de carcinoma de células claras del riñón, sometida a nefrectomía radical izquierda en 2008, quien presentó lesión mamaria palpable en mama derecha, evidenciándose un nódulo hipoecoico de 6,8 x 3,5 mm en el cuadrante superior externo, cuyo estudio histopatológico mostró una lesión metastásica de origen primario renal.

Discusión. En la literatura se han descrito aproximadamente 25 casos de metástasis de carcinoma de células claras del riñón a la mama, constituyéndose este en un caso excepcional y un reto diagnóstico para el patólogo y para el equipo tratante.

Palabras clave: neoplasias renales; carcinoma de células renales; neoplasias de la mama; metástasis de la neoplasia.
\end{abstract}

\begin{abstract}
Introduction: The presence of breast metastasis from a neoplasm of extramammary origin is an infrequent entity, representing 0.2 to I.3 \% of the non-hematological malignant tumors in breast reported in series of cases; $88.2 \%$ are patients with history of a previously treated primary tumor, and II. $8 \%$ are cases with a hidden primary tumor. The main primary origins of these metastases are cutaneous melanoma, and carcinomas of pulmonary and gynecological origin.

Clinical case: We present the clinical case of a 59-year-old woman with a history of clear cell carcinoma of the kidney undergoing left radical nephrectomy in 2008, with a palpable breast lesion in the right breast, evidencing a hypoechoic nodule measuring $6.8 \times 3.5 \mathrm{~mm}$ in the external upper quadrant, whose histopathological study showed a metastatic lesion of primary renal origin.

Discussion: Approximately 25 cases of metastasis of clear cell carcinoma of the kidney to the breast have been described in the literature, constituting ours an exceptional case, and a diagnostic challenge for the pathologist and the treating team.

Keywords: kidney neoplasms; carcinoma, renal cell; breast neoplasms; neoplasm metastasis.

Fecha de recibido: 09/01/2018 - Fecha aceptación: 08/03/2018

Correspondencia: Daniela Bertel, MD, Calle 30 No. 20-162. Cartagena, Colombia, Teléfono: (+57) 3173822553.

Correo electrónico: damibero@gmail.com. Cartagena, D.T., Colombia.

Citar como: Matute G, Raigoz O, Bertel D. Carcinoma de células claras renales metastásico a mama. Rev Colomb Cir. 2018;33:311-17. https://doi.org/10.30944/20117582.77
\end{abstract}




\section{Introducción}

La metástasis a mama de una neoplasia de origen extramamario es una entidad infrecuente, en contraste con los tumores primarios de glándula mamaria; en una de las series más grandes publicadas que valoró los casos de cáncer de mama entre 1907 a 1999, se encontró que las metástasis mamarias representaban el $3 \%$ de los casos de tumores malignos de este órgano, y un tercio de las mismas correspondían a lesiones primarias ocultas de origen extramamario. Sin embargo, en esta serie se tomaron en cuenta los casos en los cuales existía compromiso secundario por leucemia o linfoma, el cual correspondía al $52 \%$ de los casos. Cuando solo se tiene en cuenta el compromiso secundario a una neoplasia sólida, esta entidad representa entre el o,2 al I,3\% de los tumores malignos en mama reportados en series de $\operatorname{casos}^{\mathrm{r}-4} \mathrm{y}$ entre el 0,5 al 6,6 \% de los casos reportados en series de autopsias 5 .

Hasta un $88,2 \%$ de los pacientes tienen historia de tumor primario previamente tratado, y un II, $8 \%$ se presentan con tumor primario oculto. Los principales orígenes primarios de neoplasias sólidas metastásicas a mama corresponden a melanoma cutáneo y carcinomas de origen pulmonar y ginecológico los cuales en total representan el $78, \mathrm{I} \%$ de los casos ${ }^{\mathrm{I}}$. Con menos frecuencia, aunque en un porcentaje no despreciable de pacientes, se han reportado metástasis de neoplasias malignas de origen mesenquimal (hasta un $20 \%$ en series de casos), principalmente leiomiosarcomas ${ }^{4}$.

Se presenta el caso clínico de una paciente con metástasis mamaria de carcinoma de células claras del riñón.

\section{Caso clínico}

Paciente femenina de 59 años de edad, con antecedente de carcinoma de células claras de riñón hace 8 años (2008), que ameritó nefrectomía radical izquierda, posterior a la cual recibió tratamiento con quimioterapia y radioterapia. Ha presentado dos episodios de metástasis pulmonar y ósea, que recibieron tratamiento.

Adicionalmente, refiere antecedente de carcinoma mamario in situ en mama izquierda, tratado con cirugía conservadora.

En 20I8, presentó lesión mamaria palpable que motivó su consulta. En la mamografía se evidenció un nódulo isodenso en el tercio posterior del cuadrante superior externo de la mama derecha, y en la mama izquierda se observaron cambios postquirúrgicos debido al antecedente descrito (figuras I y 2). Se consideró BI-RADS o en la mamografía, por lo que se realizó una ecografía mamaria en la que se delimitó un nó-
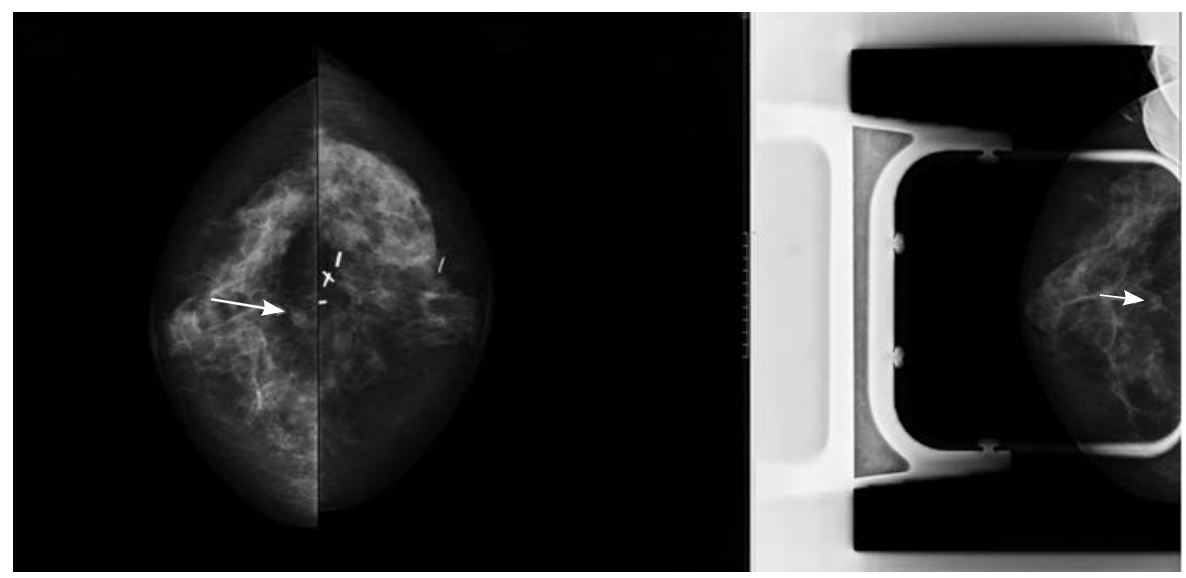

Figura 1. Mamografía. Proyecciones craneocaudales y compresión focal de mama derecha. Nódulo isodenso en el tercio posterior del cuadrante superior externo de la mama, señalado con flecha. Mama izquierda con fibrosis secundaria a procedimiento quirúrgico previo, asociado adicionalmente a clip metálico. 


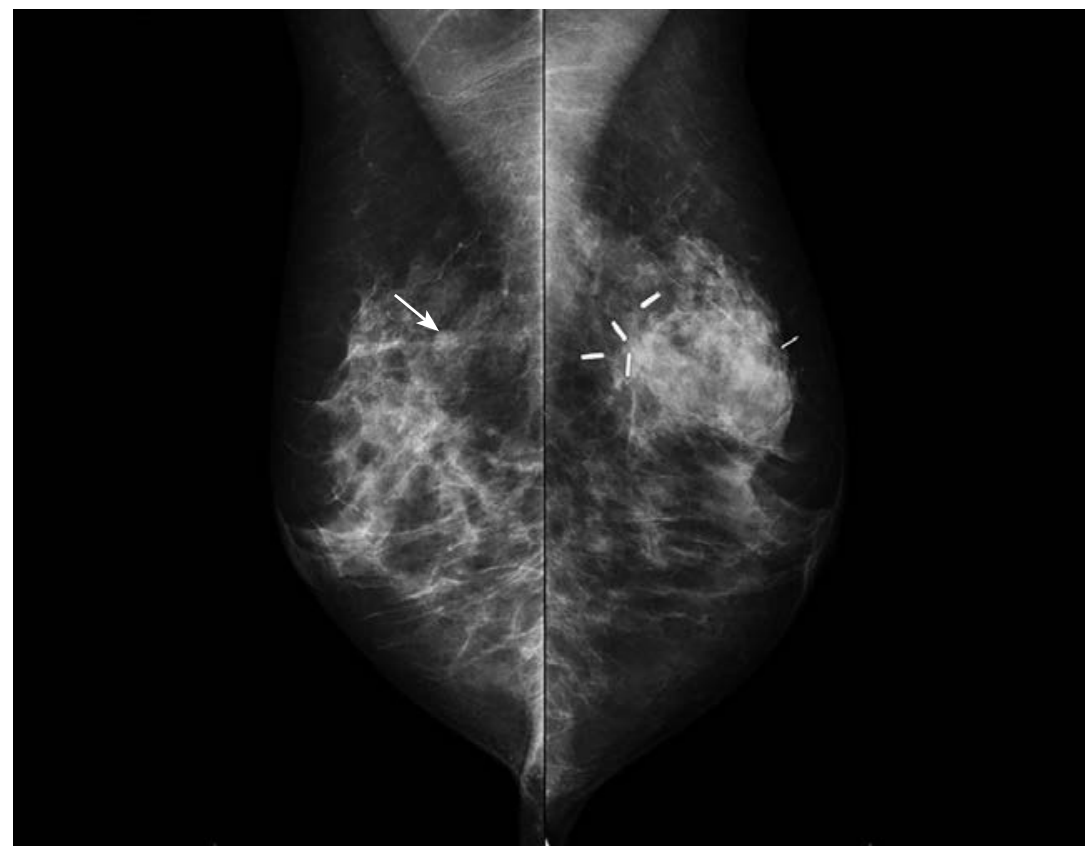

Figura 2. Mamografía. Proyecciones oblicuas. Nódulo isodenso en el tercio posterior del cuadrante superior externo de la mama derecha señalado con flecha. Cambios cicatriciales en la mama izquierda.

dulo hipoecoico de 6,8 x 3,5 mm, ubicado en el cuadrante superior externo de la mama derecha; lesión bien definida con eje mayor paralelo a la piel, sin efecto acústico posterior, sin señal Doppler color y de consistencia dura a la elastografía (figura 3), con aspecto imaginológico probablemente benigno, por lo que se consideró un BI-RADS 3 ecográfico, y se procedió a realizar una biopsia por trucut.

En los cortes histopatológicos de la biopsia se observó proliferación de células con citoplasmas claros, con poco pleomorfismo y figuras de mitosis (figura 4). Se acompañó con estudios de inmunohistoquímica que mostraron positividad para CK, CDio y RCC, con un índice de proliferación del Io \% (figura 5). Adicionalmente, se observó positividad para CD68 en histiocitos difusos acompañantes de las células neoplásicas. Se encontró, así mismo, positividad débil focal para Sıoo; el CD34 fue positivo en los espacios vasculares. No se observó reactividad en las células tumorales para $\mathrm{HMB}_{45}$, p63, y miosina de cadenas pesadas.
Teniendo en cuenta los antecedentes de la paciente, y apoyados en la histopatología de la lesión y los estudios de inmunohistoquímica, se concluyó que la paciente cursaba con metástasis mamaria de carcinoma de células claras del riñón.

\section{Discusión}

En 1903, Trevisthick reportó la primera metástasis a la mama de un tumor extramamario identificado como un linfoma de alto grado ${ }^{2}$; sin embargo, algunos autores excluyen los casos de infiltración por linfomas, al considerar que el tejido linfoide se encuentra en cualquier parte del organismo, por lo que no cumplen todos los criterios para clasificarlos como verdaderas metástasis y por tanto se le calificarían como infiltraciones secundarias. En 1936, Dawson describió el caso de una mujer de 25 años con compromiso difuso de ambas mamas por un adenocarcinoma gástrico de células en anillo de sello, considerándose el primer caso descrito de un tumor sólido con metástasis en mama ${ }^{\mathrm{I}}$. 


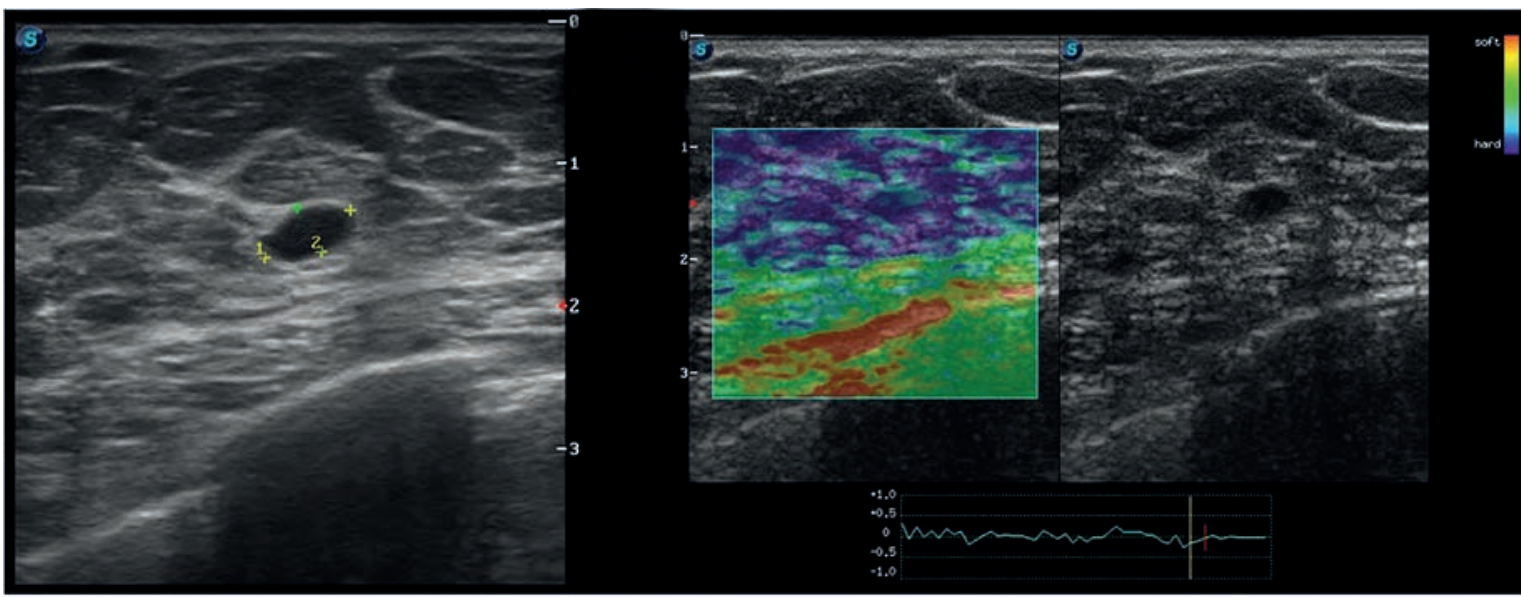

Figura 3. No se observa señal Doppler color y es de consistencia dura en la elastografía.

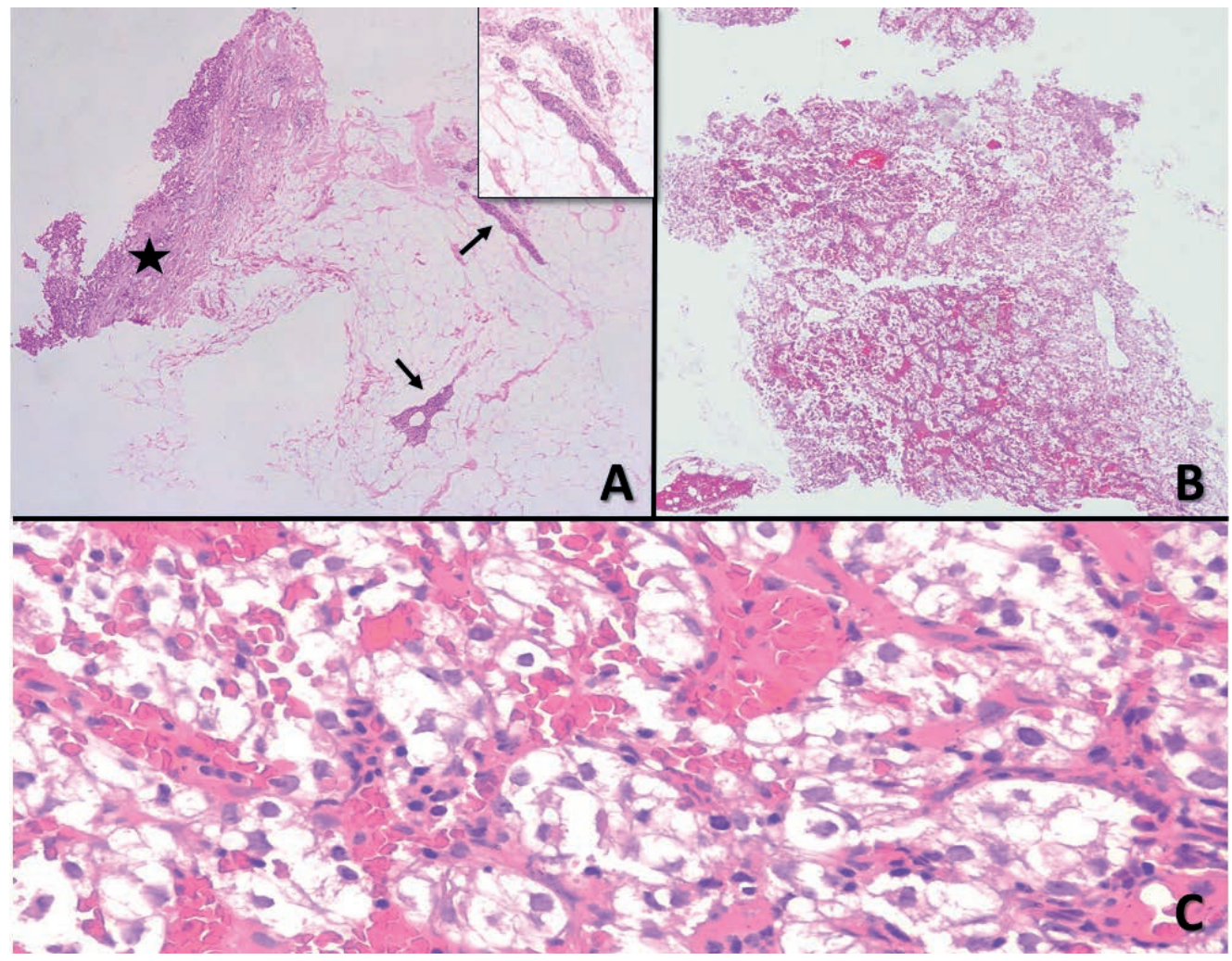

Figura 4. Histopatología. Se observa parénquima mamario (flecha) (A, H\&E, 4x) comprometida por una proliferación de células grandes con citoplasmas amplios claros y núcleos hipercromáticos con ocasionales nucléolos prominentes, escaso pleomorfismo y figuras de mitosis; adicionalmente, se identifican áreas de hemorragia difusa ( $A, H \& E$ 4x, estrella) $(B, H \& E, 4 x)(C, H \& E, 40 x)$. 


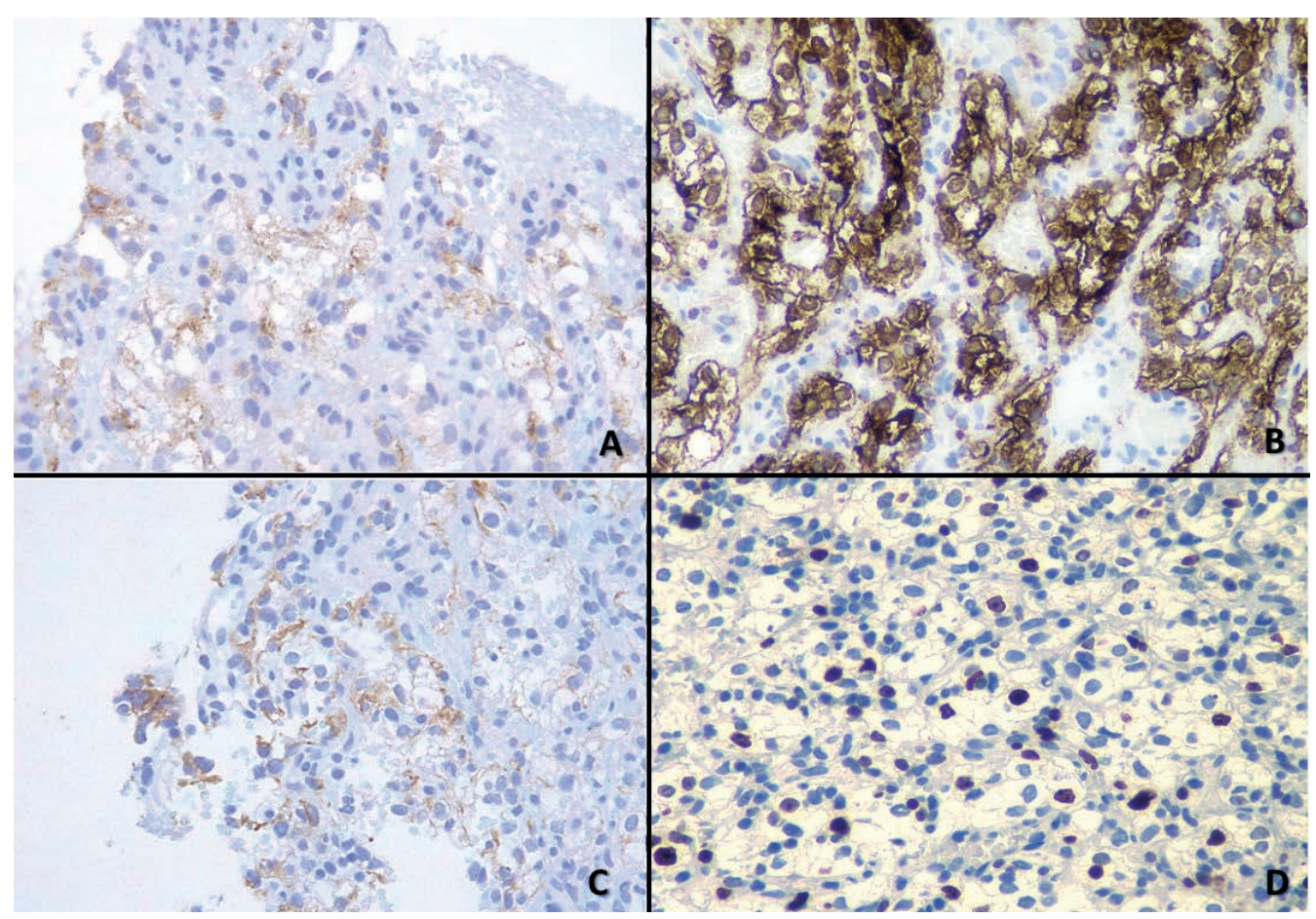

Figura 5. Inmunohistoquímica. Se observa positividad focal tenue para carcinoma de cédulas renales (RCC, de renal cell carcinoma) (A, 40x); positividad fuerte y difusa para CD10 (B, 40x); positividad tenue de membrana para CK (citoqueratina) (C,40x); índice de proliferación (Ki67) de 30 \% (D,40x).

El carcinoma de células renales representa aproximadamente el $5 \%$ de todas las neoplasias epiteliales en el mundo, de las cuales el carcinoma de células claras del riñón es el tercer tumor más común del tracto genitourinario, dando cuenta de aproximadamente el $3 \%$ de todas las neoplasias y el $85 \%$ de los carcinomas de células renales $^{6-9}$. Es más común en hombres que en mujeres, en una proporción de I.5:I, y la mayoría de los casos ocurren entre los 50 a 70 años de edad. El cuadro clínico clásico está conformado por dolor, hematuria y masa palpable en flanco, que se observa en hasta un $9 \%$ de los $\operatorname{casos}^{10}$.

Cerca del 25 al $30 \%$ de los pacientes tienen tendencia a metastatizar usualmente pulmón (70 \%), ganglios linfáticos $(55 \%)$, hueso $(42 \%)$, hígado (4I \%), glándula adrenal (I5\%) y cerebro (II \%), y otro $20 \%$ experimentan recurrencia o enfermedad metastásica después de la nefrectomía ${ }^{6-9}$. Se han descrito otros casos de metástasis en lugares poco frecuentes como páncreas $(0,25-3 \%)^{11,12}$, cabeza y cuello $(8-14 \%)^{13-17}$ y ovario ${ }^{18}$.

Las metástasis mamarias de origen renal corresponden sólo al $3 \%$ de todos los tumores metastásicos en esta localización ${ }^{6-9}$.

En la literatura se han descrito aproximadamente 25 casos de metástasis de carcinoma de células claras del riñón a la mama, II de los cuales acaecieron con una metástasis como signo inicial de la enfermedad y I4 como una lesión metacrónica posterior a una nefrectomía y de estos, 2 fueron lesiones bilaterales ${ }^{6}$.

Desde el punto de vista clínico, las lesiones metastásicas a la mama se manifiestan con edema no doloroso con rápido crecimiento ${ }^{7}$. A diferencia de las neoplasias primarias, la piel frecuentemente no está involucrada y el compromiso axilar es variable, describiéndose entre un I4 a $42 \%$ de los casos; se ha detectado pre- 
sentación bilateral en un 8 a $26 \%$ de los casos descritos ${ }^{7,8}$.

De otro lado, para la valoración radiológica de la mama se requieren tres herramientas diagnósticas: mamografía, ecografía mamaria y resonancia magnética nuclear, que ayudaría a definir cuáles lesiones requerirán evaluación con métodos invasivos que incluyan aspiración con aguja fina, biopsias con aguja gruesa o biopsias escisionales ${ }^{3}$. En la mamografía se observan lesiones bien circunscritas, sin evidencia de microcalcificaciones ${ }^{7}$. En las ecografías mamarias suele observarse una lesión con características morfológicas sospechosas debido a vascularización intensa y ausencia de elasticidad. Por su parte, en la resonancia magnética nuclear, se observa captación rápida del agente de contraste en el sitio de la lesión, lo cual confirmaría la hipótesis de una lesión expansiva³.

Desde el punto de vista histológico, el carcinoma de células renales recuerda a un carcinoma mamario de células claras, por tanto se requieren estudios de inmunohistoquímica para $\mathrm{PAX}_{2}$, PAX8, MUCI, CDIo, y anticuerpo monoclonal del carcinoma de células renales (RCCma), que ayudan a confirmar el origen renal ${ }^{\mathrm{I}}$.

El curso del carcinoma de células claras renales es extremadamente variable e impredecible, tanto en cuanto a su clínica como a sus metástasis. Muchos pacientes con carcinoma de células renales desarrollan múltiples metástasis y es frecuente la muerte en los siguientes diez años ${ }^{7}$. El $60 \%$ presenta en algún momento de la evolución de su enfermedad una metástasis a distancia, con una mediana de supervivencia a 3 y 5 años del 4,4 \% y I7 \% de los casos, respectivamente. El tratamiento de las lesiones secundarias de la mama difiere del de los tumores primarios. Por un lado, los márgenes de una lumpectomía deben ser muy amplios debido a que las lesiones metastásicas tienden a ser múltiples, así que con frecuencia es difícil conseguir un margen quirúrgico libre. Por otro lado, la valoración de ganglios linfáticos axilares aún es controvertida; sin embargo, se cree que debido al mecanismo de diseminación, al tratarse de una lesión metas- tásica, no es útil la biopsia de ganglio centinela ni el vaciamiento ganglionar. El tratamiento de elección para pacientes con metástasis aisladas es la mastectomía sin vaciamiento axilar, ${ }^{5,6,8}$. Pese a lo anterior, en una serie de casos de metástasis mamarias, como aquella publicada en 2013 por DeLair et al. evidenciaron que en un I4 \% de los casos se podía encontrar lesión que involucraba la mama y los ganglios axilares ipsilaterales, y hasta en un $8 \%$ se halló compromiso solamente de ganglios axilares ${ }^{4}$. De lo expuesto, es posible concluir que aún se requiere mayor estudio de estas lesiones de modo que puedan dilucidarse las mejores estrategias para el manejo quirúrgico de las metástasis mamarias con base en el origen histológico de las mismas.

En cuanto al tratamiento quimioterapéutico y con hormonoterapia para las metástasis de carcinoma de células claras del riñón, se considera ineficaz, con tasas de respuesta inferiores al $5 \%$ y de corta duración. Con la inmunoterapia se han logrado tasas de respuesta del I5 al $20 \%$, algunas de ellas de larga duración $n^{6,8}$. La introducción de inhibidores de la tirosina kinasa (TKIs) y mTOR ha modificado el escenario terapéutico en pacientes con carcinoma de células renales metastásico, reemplazando la inmunoterapia como tratamiento de elección; no obstante, se requieren nuevos estudios clínicos y moleculares con el fin de optimizar el uso de esos nuevos agentes terapéuticos para las metástasis de carcinomas de células renales ${ }^{9}$.

\section{Conclusión}

Las metástasis a mama de otras neoplasias, son infrecuentes; sin embargo, deben formar parte de los diagnósticos diferenciales planteados en casos donde previamente se conozca la historia oncológica, y en aquellos en los cuales los hallazgos histológicos no sean los esperados en una neoplasia primaria.

\section{Referencias}

I. Hoda S. Metastases in the breast from nonmamary neoplasms. In: Hoda S, Brogi E, Koerner F, Rosen P. Rosen's Breast Pathology. Fourth edition. Philadelphia: Lippincott Williams \& Wilkins; 20I4. p. 937-55. 
2. Pinto D, Carballo P, Lamas G, Montesinos M, Debonis D. Metástasis en la mama de carcinoma renal. Rev Argent Cirug. 20II;IOO(I-2):36-8.

3. Botticelli A, De Francesco G, Di Stefano D. Breast metastasis from clear cell renal cell carcinoma. J Ultrasound. 2013;16:127-30.

4. DeLair D, Corben A, Catalano J, Vallejo C, Brogi E, Tan L. Non-mammary metastases to the breast and axilla: a study of 85 cases. Mod Pathol. 2013;26:343-9. doi: I0.IO38/ modpathol.20I2.I9I.

5. Bortnik S, Cohen D, Leider-Trejo L, Ron I. Breast metastasis from a renal cell carcinoma. IMAJ. 2008;I0:736-7.

6. Falcoa G, Buggib F, Sannab P, Dubinic A, Folli S. Breast metastases from a Renal Cell Carcinoma. A case report and review of the literature. Int J Surg Case Rep. 20I4;5:I93-5. doi: Io.IOI6/j.ijscr.20I4.oI.oI9.

7. Alzaraa A, Vodovnik A, Montgomery H, Saeed M, Sharma N. Breast metastasis from a renal cell cancer. World J Surg Oncol. 2007;5:I-4. doi: I0.II86/I477-7819-5-25.

8. Fírvida J, Calvo J, Martínez F, Salgado M. Metástasis mamaria como manifestación inicial de un carcinoma renal. Arch Esp Urol. 2005;57; 67-9.

9. Santoni M, Conti A, Procopio G, Porta C, Ibrahim T, Barni S, et al. Bone metastases in patients with metastatic renal cell carcinoma: are they always associated with poor prognosis? J Exp Clin Cancer Res. 2015;34:I-9. doi: I0.II86/sI3046-0I5-OI22-0.

Io. Shuck C, Morales G, Fernández A, Vázquez, Castellano M., Pacheco C, et al. Metástasis de carcinoma de células claras de riñón a bazo. Rev Mex Urol. 2007;67:124-8.

II. Oneil N, Chopra P. Pancreatic metastasis from renal carcinoma managed by whipple resection. A case report and literature review of metastatic pattern, surgical management and outcome. J Pancreas (Online) 2009;10:413-8.
I2. Markinez I, Jiménez R, Ruiz I, Villarreal E, Lizarazu A, Borda N, et al. Pancreatic metastases due to renal carcinoma: our cases and a literature review. Cir Esp. 2013;91:90-5. doi: I0.I0I6/j.cireng.2012.07.003.

I3. Ramôa F, Souza R, Ficarra G, Silveira A, Carlos R, Kowalski LP, et al. Metastatic renal cell carcinoma to the oral cavity and clear cell mucoepidermoid carcinoma: comparative clinicopathologic and immunohistochemical study. Oral Surg Oral Med Oral Pathol Oral Radiol Endod. 20IO;IO9:22-7. doi: https://doi. org/IO.IOI6/j.tripleo.2009.12.006.

I4. Jayasooriyaa P, Gunarathnaa I, Attygallab A, Tilakaratne W. Metastatic renal cell carcinoma presenting as a clear cell tumour in the head and neck región. Oral Oncology. 2004;40:50-3. Doi: I0.IOI6/j.0oe.2003.12.005.

I5. Patiño B, Lorenzo F, Martín R, Alvarez A, López-Cedrún J. Metastasic renal cell carcinoma presenting as a parotid tumor. Oral Surg Oral Med Oral Pathol Oral Radiol Endod. 2005;99:554-7. doi: Io.IoI6/j.tripleo.2004.08.007.

I6. Abbaszadeh H, Motallebnejad M, Rajabi M. Metastatic renal cell carcinoma presenting as a clear-cell tumor in tongue: a case report. Iran J Otorhinolaryngol. 20I4;26:I85-90.

I7. Mogedas A, Rubio J, Gutiérrez J, Bordonaba S, Pamias J, Raspalla G, et al. Metástasis parotídea de un carcinoma renal: A propósito de un caso. Rev Esp Cir Oral Maxilofac. 20I3;35:83-6. doi:Io.IoI6/j.maxilo.20II.08.009.

I8. Ruiz-Reyes R, Jordán-Alonso A, Madruga-Vásquez K, Fernández-Cedeño O. Metástasis ovárica de carcinoma de células renales: presentación de un caso y revisión de la literatura. Rev Med Electrón. 2012;34:609-702. Fecha de consulta: 17 de diciembre de 20I7. Disponible en: http://www.revmatanzas.sld.cu/revista\%2omedica/ ano\%2020I2/vol6\%2020I2/temao8.htm. 